\title{
Laboreal
}

Volume $16 \mathrm{~N}^{\circ} 1 \mid 2020$

Quando o trabalho real é tabu

\section{El amianto : glorias y tragedias de una fibra aterradora \\ Introducción al dossier}

0 amianto : glórias e tragédias de uma fibra aterradora

Introdução ao dossier

L'amiante: gloires et tragédies d'une fibre effrayante

Introduction au dossier

Asbestos : glories and tragedies of a terrifying fiber

Dossier introduction

Marianne Lacomblez y Augusto Rogério Leitão

Traductor. Fernanda Romero

\section{OpenEdition}

Journals

Edición electrónica

URL: http://journals.openedition.org/laboreal/16187

DOI: 10.4000/laboreal. 16187

ISSN: 1646-5237

Editor

Universidade do Porto

Referencia electrónica

Marianne Lacomblez y Augusto Rogério Leitão, « El amianto : glorias y tragedias de una fibra aterradora

Introducción al dossier », Laboreal [En línea], Volume 16 N¹ 1 2020, Publicado el 01 julio 2020, consultado el 15 septiembre 2020. URL : http://journals.openedition.org/laboreal/16187

Este documento fue generado automáticamente el 15 septiembre 2020.

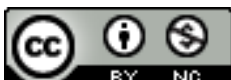

Laboreal está licenciado com uma Licença Creative Commons - Atribuição-NãoComercial 4.0 Internacional. 


\section{El amianto : glorias y tragedias de una fibra aterradora Introducción al dossier}

0 amianto : glórias e tragédias de uma fibra aterradora

Introdução ao dossier

L'amiante : gloires et tragédies d'une fibre effrayante

Introduction au dossier

Asbestos : glories and tragedies of a terrifying fiber

Dossier introduction

Marianne Lacomblez y Augusto Rogério Leitão

Tradución : Fernanda Romero

\section{NOTA DEL EDITOR}

Traducción : Fernanda Romero - fernandaromero.trad@gmail.com

1 1. Las comunidades humanas empezaron, hace varios milenios, a utilizar las fibras de amianto o asbesto, una roca mineral, en la fabricación de cerámicas, de colorespinturas y de artefactos textiles. Sin embargo, nuestra percepción actual de ese mineral está fundamentalmente asociada a la existencia y utilización de productos de fibrocemento y también, desafortunadamente, a sus efectos perniciosos, individuales y colectivos.

Invención (patentada) del inicio del siglo XX, el fibrocemento está en el origen de la creación de la sociedad Eternit-Suiza - 'Eternit' porque esa mezcla de amianto y de cimento asumiría tales calidades (durabilidad, resistencia térmica y mecánica, buena calidad de aislamiento, incombustibilidad, etc.) que se creía que su uso sería "para la eternidad". El grupo empresarial era propiedad, hasta mediados de 1980, de la familia Schmidheiny, nombre que, como veremos, se haría famoso por muchas malas razones. 
Eternit instalaría fábricas por toda Europa, produciendo tejas, depósitos de agua y tubos para canalizaciones. No obstante, el gran desarrollo de la producción y comercialización de los productos con amianto ocurriría después de la Segunda Guerra Mundial, en el contexto de la dinámica de la reconstrucción, proporcionado, de hecho, nuevos productos (placas de revestimiento y de aislamiento térmico, textil amianto, ...) y nuevas utilizaciones (discos de embrague, pastillas de frenos de vehículos, ...).

3 En simultaneo, se asistía a una ampliación geográfica de los locales de extracción del mineral : además de Canadá y de la ex Unión Soviética, se empezarían a explotar nuevos yacimientos en Sudamérica, África y Australia. E innumerables fábricas de fibrocemento se instalarían en todo el mundo, un movimiento estrechamente relacionado con el crecimiento económico de los países ricos, pero también con las evoluciones "desarrollistas" de los países del "tercer mundo".

4 2. Ahora bien, la constatación de los efectos nefastos del amianto en la salud de los trabajadores pondría en causa evidencias que han dado forma a nuestras sociedades durante décadas. De hecho, las investigaciones científicas dirigidas por grandes médicos, tales como el inglés Richard Doll y el norteamericano Irving Selikoff, provocaron una verdadera sacudida social y política en varios países. Esos estudios, difundidos en los inicios de los años 60 , acabarían por atribuir una nueva visibilidad a las graves consecuencias del uso del amianto en ambientes de trabajo: asbestosis y mesoteliomas, es decir, fibrosis y cáncer de los pulmones y cánceres de la pleura, del peritoneo y del pericardio, pero igualmente de la laringe, del estómago o de los ovarios. En esa época, ya se hablaba de "catástrofe sanitaria", una vez que los casos que se revelaban y contabilizaban (una gran parte de estos con su génesis dos o tres décadas antes, dada la lenta evolución de algunos de estos cánceres) anunciaban la calamidad que se prolongaría hasta nuestros días.

5 3. Pero la denuncia científica, ganando en importancia, y el despertar de los movimientos nacionales e internacionales de defensa de las víctimas, no dejaron impasible al lobby industrial y económico del amianto. En verdad, este grupo de intereses desencadenaría, estratégicamente, un debate, en el cual intervinieron también algunos científicos, con respecto a la evaluación de los daños resultantes del uso de todos los tipos de amianto.

6 Sería de este modo que la segunda tesis se consiguió imponer, la tesis según la cual los maleficios solo ocurrirían con la utilización de las variedades de amianto anfibolio, mientras que, en relación con el otro tipo de amianto, el amianto crisolito, dada la especificidad de sus fibras, los efectos nocivos serían mínimos. Además, añade dicha tesis, esos efectos mínimos serían eliminados mediante un uso "controlado" de la actividad de extracción y de producción del mineral.

7 Si es verdad que a partir de mediados de los años 70 todos o casi todos los países habían prohibido el uso o la utilización de todas las variedades de amianto anfibolio, también es verdad que ese tipo de amianto representaba el $5 \%$ del total utilizado en el planeta. Dicha prohibición exprimiría así, por un lado, un intento del lobby para dar una respuesta moral a las alarmas suscitadas por las investigaciones científicas y, por otro, el refuerzo del objetivo de poder seguir, serena y plenamente, explotando el amianto crisotilo a nivel mundial.

8 De hecho, este paradigma del "uso controlado (o en seguridad) del amianto crisotilo" sería consagrado en el Convenio n.. 162 de la OIT de 1986, conquistando así una fuerte legitimidad internacional. Señalaremos, igualmente, que el Estado canadiense fue el 
actor principal de esa afirmación y del largo mantenimiento de ese paradigma en el seno de los fórums internacionales (OIT, Convenio de Róterdam, OMC, ...). Y para comprender, todavía mejor, el peso de los intereses económicos en el desarrollo de las dinámicas del proceso contencioso del amianto, subrayaremos que Canadá dominó, durante décadas, la producción y las exportaciones mundiales de amianto - habiendo, sin embargo, adoptado en la práctica el llamado "modelo del doble estándar", reduciendo gradualmente el consumo interno, pero manteniendo hasta hace pocos años la exportación de la casi totalidad de su producción.

De todos modos, la tesis que defiende la inocuidad de la exposición "controlada" a las fibras de amianto de la variedad crisotila se ha ido desmitificando por numerosos estudios científicos $\mathrm{y}$, desafortunadamente, también por los gravísimos daños ocasionados a la salud y a la vida de muchos(as) trabajadores(as) que se hicieron cada vez más visibles. Y, como consecuencia, los movimientos por la abolición definitiva, sobre todo los de los países europeos estaban obteniendo satisfacción, al menos en lo que respecta a la prohibición del uso de amianto propiamente dicha. Es más, la Unión Europea (Comunidad Europea) decidió, mediante la Directiva 1999/77 de 26 de junio, que todos sus Estados-miembros pasarían a consagrar, en el respectivo orden jurídico, la prohibición definitiva del amianto a partir del 2005. Incluso si algunos Estados, como Francia, ya hubiesen adoptado dicha prohibición.

10 4. Los casos presentados en este dossier revelan, no obstante, que algunos protagonistas de este conflicto social aún se mantienen activos - ora transformando ese conflicto, como en Brasil, en sucesivas disputas jurídico-políticas ora, como en Francia, donde la movilización de las asociaciones y de los sindicatos prueba como son todavía indispensables en la defensa de los derechos fundamentales de los trabajadores en este dominio.

11 La cuestión del amianto nos surge, pues, como muy actual : sigue siéndolo en términos de salud ocupacional, pública y medioambiental, y lo será cada vez más como un problema asociado a la gestión de sus residuos y a los modos de manutención, reparación, remoción o demolición de edificios, instalaciones y equipos en los que existe amianto o materiales que lo contengan. $Y$, en estas situaciones, el tema central es, por supuesto, el de la protección de la salud de los trabajadores, pero igualmente la defensa de la salud pública.

12 A este respecto, Portugal, después de la Revolución de abril de 1974, adoptaría, en una primera fase, los normativos consagrados en convenios de la OIT, mientras tanto ratificados $\mathrm{y}$, en una fase siguiente, después de su adhesión a las Comunidades Europeas, en 1986, pasaría a transponer las directivas comunitarias sobre la cuestión del amianto. Así, el Decreto-ley n.. 101/2005, de 23 de junio, transpone la Directiva de 1999 ya mencionada, pasando Portugal, a partir de esa fecha, a prohibir de manera definitiva el uso del amianto en su territorio. Y, a continuación, en julio de 2007, adoptaría legislación que transpone la Directiva n. 2003/18-CE, de 27 de marzo, sobre, precisamente, la protección de los trabajadores en obras donde estén presentes materiales con amianto. Una legislación con una gran importancia y de gran actualidad, una vez que el Estado portugués está actualmente enfrentando la tarea/misión de remoción (o demolición) del fibrocemento en los edificios públicos, en particular en los centros de enseñanza. Sin embargo, dicha misión viene siendo gestionada por los sucesivos gobiernos con grandes dificultades e inacciones. 
13 En las dificultades, intervienen, obviamente, las de la debida protección de los trabajadores que llevan a cabo tales actividades de supresión del amianto. Es bueno recordar, entonces, los estudios de la Ergonomía que han evidenciado la peligrosidad de esa actividad y la necesidad de atribuirle la mayor atención al elaborar, de modo preciso y adecuado, tanto las normas de seguridad como los respectivos equipos de protección (Garrigou, Mohammed-Brahim \& Daniellou, 1998 ; Duarte, Théry \& UllilenMarcilla, 2016).

Queda mucho por hacer para liberar al mundo del amianto...

\section{BIBLIOGRAFÍA}

Duarte, F., Théry, L., \& Ullilen-Marcilla, C. (2016). "Los equipos de protección individual (EPI) : protectores, pero no siempre" : presentación del dossier. Laboreal, 12(1). http:// journals.openedition.org/laboreal/2830.

Garrigou, A., Mohammed-Brahim, B., \& Daniellou, F. (1998). Étude ergonomique sur les chantiers de déflocage d'amiante. Rapport final, OPPBTP/DRT.CT3. Bordeaux.

\section{AUTORES}

\section{MARIANNE LACOMBLEZ}

Centro de Psicología de la Universidad de Porto, Facultad de Psicología y de Ciencias de la Educación, Universidad de Porto. Rua Alfredo Allen, 4200-135, Porto, Portugal lacomb@fpce.up.pt

\section{AUGUSTO ROGÉRIO LEITÃO}

Centro Observare, Universidade Autónoma de Lisboa Rua Santa Marta 56, 1169-023 Lisboa \& Faculdade de Economia, Universidade de Coimbra Av. Dr. Dias da Silva 165 3004-512 Coimbra, Portugal 